\title{
Experinest 34
}

Oct. 20. Medium-sized mongrel. Weight, $\hat{3}^{1}$ lbs. Shot with a Remington rifle, using a .22 short shell. Ball entered un a level witb, and one and a lialf inches to the tight of the umbilicus. Dog was allowed to come from under the anxsthetic and remain so for an hour. Again placed under the anzsthetic and Senn's test opplied. Gas soon made its appearanee at the wound of entrance and burned in a jet. Animal again returned to the kennel.

Oct. 21 . Found dead.

Post-mortem. Abdoninal cavity eontained about eight ounces of bloody fluid and a large number of elots. Considerable extravasation of freces and entozoa. Five lange wounds of the intestines and one of the mesentery involving a ressel. Wound of the splenic border. Death from lixmorrhage.

\section{EXIERJME:T 55.}

Oct. 20. Medium-sized mongrel. Weight, zo lbs. Shot witl a flobert from a Remington ritte. Ball entered on a level wi.h and two inches below the umbilicus. Senn's test was applied indicating an intestiaa! perforation. The gas did not bum in a jet but only now and then the bubbles ignited. Removed, but died in an lour's time.

Post-mortem. Alsdominal caviyy filled with bloody fiud and elots. There were seven perlorating wounds of the intestine and lour of the mesentery. Two of the latter involved mesenteric vessels. Death from hemorrhage.

\section{EXPERIMIENT 36.}

Sov. 5. Medium.sized mongrel. Weight, 20 lbs. Shot with a S. \& W. pistol, .22 caliure. Ball entered on a level with and to the right of the umbilicus, passing in a very shallow course. Given 12 minims Magendie's sol ution an 1 remused. So shock, the dog rallying at once.

Nov, 6. Up and takes milk.

Nov. 7. Lively and eats freely.

Sov. S. Same.

Nov. 12. Apparently recovered and made his escape from the hospital. In this experiment the ball apparently did not enter the abdominal cavity, or if it did so, it failed to create any serious damage.

\section{EXIPRIMENT 37.}

Nov, 12. Small mongrel. Weight, 17 lbs. Shot with a S. AW. pistol, .22 calibre. Given 15 minims. Magendie's solution and removed.

Nor. 13. Found dead.

Post-mortem. Cavity contained some blood and nine perforating wounds of the intestines. Death from shock.

\section{Experinexts Ufox Separate Organs-Resections.}

\section{EXPERIMENT 33 .}

Aug. 28. Full-grown bull dog. Weight, $3 t$ lbs. Abdominal cavity opened and a loop of intestine withdrawn. Tbe ressels at the mesenteric border ligated and one 
inch resected. The ends were united after the method of Wulfler (uniting the posterior third from within). Uneventul recovery followed.

\section{EXPERLMEXT 39 .}

Aug. 31. Small mongrel. Weight, 14 tbs. Abdumioal cavity opened and a loop of intestine withdrawn, resecting four inclies as in the previous experiment. kecovery.

\section{EXPERIMENT +o.}

Oct. 2. Same dug used that served in the foregoing experiment. Abilomen opened just above the scar from the former operalion. The resection was found in a perfect condition with a sponianeous omental graft at the seat of union. The sutures all encysted excrptiag those introduced posteriorly. Eighteen inches incluling the former resection were now removed. The vessels were ligated at the vertebral border of the mesentery and a $V$-shaped piece excised uniting the edges with a running catgut suture. I he iotestines were united as io the preceding experiments only reinforcing the resection by an "omental graft." The ends were united not far fron the ileociecal valve, and the blood supply wery much interfered with; howerter no harm resulted. Recovery followed without any inconvenience to the animal after the removal of $\geq 2$ inches of intestine.

Cov. 2S. Killed to obtain the specimen.

post-mortem. Several adhesions at the seat of resection. No narrowing of the calibre. Sutures eocysted. The web of the nesentery between the vessels at the re section absent.

\section{EXYERTIENT 41.}

Oct. 12. The same subject that served in Experiment $3 \mathrm{~S}$ was used here. Abdomen openel and the site of the former resection withd:awn and found marked by an omental adhesion and a slight narrowing of the intestine internally and externally; The sutures all encysted and plainly visible. Four inches were resected including the site of the former operatioo. Very shortly after the oderntion the dog by inistake was fed upon a large piece of meat, but no harm resultet.

Now. 5. Killed to obtaio the specimen.

Post-.Iortem. Omentum adherent. Lumen slightlynarrowed. Sutures encysted.

\section{ENPERMMENT iz.}

Nov. 19. In this experiment the same dog was used that served in Experiment 24 . Laparotomy above the former site. The spleen withdrawn and a triangle excised measuring one inch at its base and a fracion more from base to apex. The edges were united by a continuous suture commencing on its external surlice, passing over the free border and down upon its internal surlace. This completely arrested the hremorrluage. Following this the spleen increased to almost double its size and became cyanosed in appearance, in which state it was returned and the cavity closed.

Dec. 2S. Recovered. Killed tu obtain specimeo. Complete union marked by a white line which represented the uoited edges. Omentun adherent. Sutures enzysted and somewliat softened. Part below the suture slightly atrophied and darker color; but otherwise unchanged. 


\section{EXPERIMENT 43.}

Jan. 2. Full-grown mongrel. Weigh1, to lbs. Curvilinear incision under the right horder of the ribs, and afterward $j$ jined iy one in the linea alba Lives exposed and perforated by a lilunt aseptic instrument as well as the excision of a narrow but long triangle. The puncture was serred upon both sides which arrested the hxmorrlage completely. The excision was united by a running cat-gut suture applied as in the previous experiment. which likewise arrested the tow from the surfaces. In drawing the liver into view rupture of its capsule occurred in severa! places. Cavity washed out and closed.

Jan. 3. Walking about. Took sereral ounces of milk in the morning but refused food at noon and evening. Urine loated with bile.

Feb. 1S. Killed to obtain specimen.

Post-mortem Liver marked by while hnes at the points of rupture. Slight scars at the punctures. The excision was marked by an omental adhesiun but otherwise unchanged. No evidence of peritonitis.

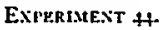

Jan. 2. Small white mongrel. Weight, ig lbs. A hypodermic syringeful of bile was olstained from another dog and injected into the peritoneal cavity without the introunction of air. This was repeated a second timeand each time followed by an exhibution of pain from the dog. The syringe was enutiously introduced, care being oliserved to try and insure the arrival of the bile in the peritoneal cavity. and from the impression it was apparently successful.

Jan. 3. Refuses all fool and lies quiet in one place.

Jan. 4. Sane.

Jan. 15. Recovered, and killed for further examination.

Post-mortem. Absolutely no signs were visihle of any change having occurred within the peritoneal cavity.

\section{E.XPERIMENT 45.}

Jan. 39. Liver-colored mongrel. Weaglu, $3 \geq 1 \mathrm{bs.} \mathrm{Abdomen} \mathrm{opened} \mathrm{and} \mathrm{the}$ intestines exposed. The intestines were insufflated with air until thev were distended. The respirations became short and slow. Puncture was made ipto the large intestine, which was followed by an e'scape of air and the collapse of the intestine, but only for a sbort distance beyond. This was repeated in the small intestines with the same tesult. The stomach, which was likewise distended, was compressed, but no gas esenped till a puncture was made into it. The intestines were largely distended, and the occurrence of acute fiexures prerented the ready escape of the air. 
SYTOPSIS OF EXPERIMIEXTAL WORIE AND RESULTS

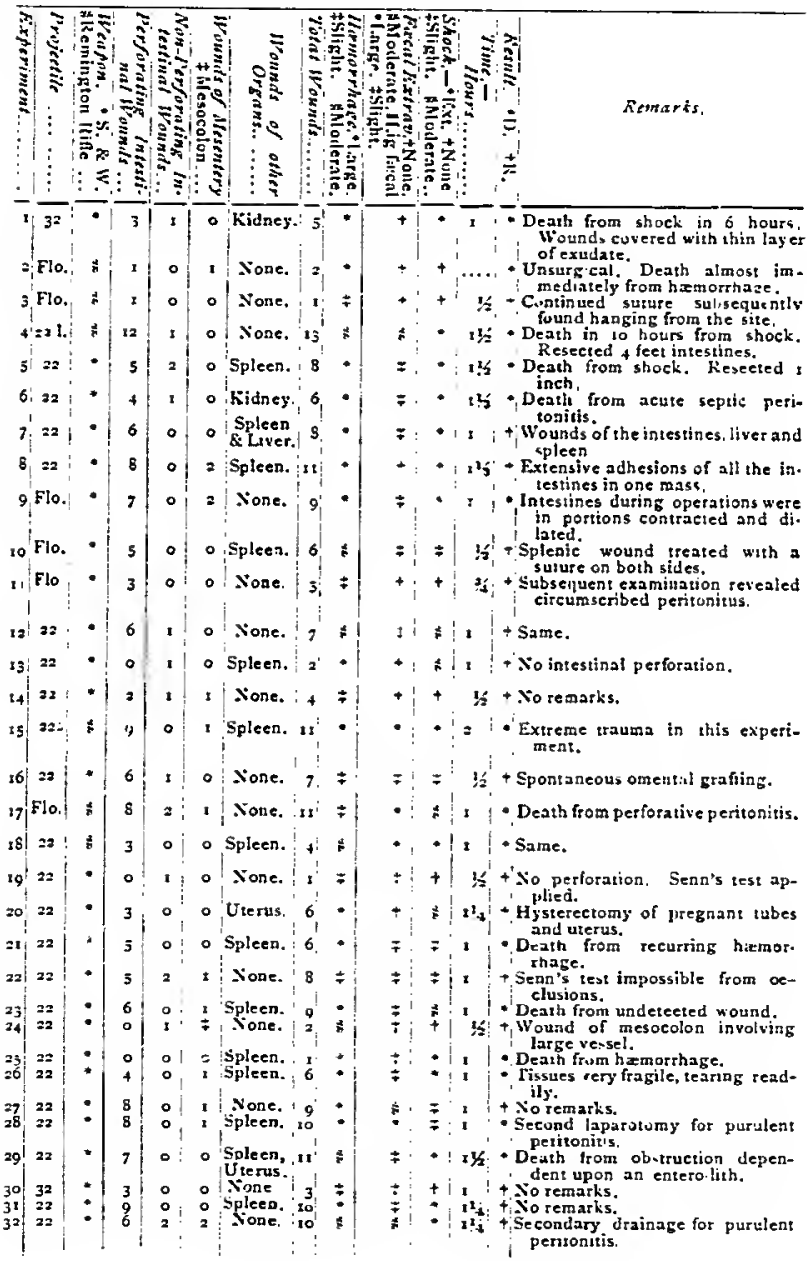

